\title{
Age and Sex Related Changes in Comeal Thickness and Anterior Comeal Curvature in Korean Young Population with Orbscan II Topography System
}

\author{
Dong-Hee Lee ${ }^{1}$, Douk-Hoon Kim², and Seung-Hwan Park ${ }^{3 *}$ \\ ${ }^{I}$ Department of Optometry, Eulji University, Seongnam 461-713, Korea \\ ${ }^{2}$ Department of Optometry, Masan University, Masan 630-729, Korea \\ ${ }^{3}$ Department of Biomedical Engineering, Eulji University, Seongnam 461-713, Korea
}

(Received February 14, 2011 : accepted February 23, 2011)

\begin{abstract}
This study investigated, using the Orbscan II topography system, the influence of age and sex related changes on the corneal thickness and anterior corneal curvature, more specifically the fine structure of the cornea, in a Korean young population. The Orbscan II topography system is a computer-assisted slit-beam scanning technology that can map the anterior section of the cornea. The mean central corneal thickness of all subjects was $547.532 \pm 44.529 \mu \mathrm{m}$. There was no statistical difference ( $>0.5)$ in the mean central corneal thickness between males and females. Sex and age related changes in the mean central corneal thickness had no specific statistical difference $(\mathrm{P}>0.5)$. There was a negative correlation between the anterior corneal curvature and the central corneal thickness in all subjects, except for the twenty year olds However, the thickness relationship between the mean central corneal and the eight paracentral corneal thicknesses had strong statistical differences in all subjects. Also age and sex related changes in the central corneal thickness and the anterior corneal curvature in all subjects had no statistically significant difference, except from 20-26 years old ( $>0.05$ ). This information could be a suitable reference basis for future studies in the young population of Asia and for the development of examination tools for corneal refractive surgery.
Keywords : Central corneal thickness, Paracentral corneal thickness, Korean young population, Orbscan II topography, Anterior corneal curvature
OCIS codes : (170.4470) Ophthalmology; (330.4460) Ophthalmic optics and devices; (330.7335) Visual optics, refractive surgery
\end{abstract}

\section{INTRODUCTION}

The topographic system has provided excellent information about the fine structure of the cornea. The data acquired by Orbscan tools has suggested significant important information in clinical diagnosis and management of corneal disease [1], contact lens use [2], and refractive surgery [3]. Corneal thickness of each region is an indicator of corneal hydration and metabolism [4]. On the other hand, the topographic results of the central corneal thickness have been used to analyze the diagnosis and treatment of glaucoma [5]. Distribution of the central and paracentral corneal thickness and curvature has been studied in the European population [6]. In particular, age related changes in the central and peripheral corneal thickness seem to give useful information for keratoplasty and refractive surgery [7]. Recently, the relationship between the central corneal thickness and the anterior corneal curvature has been studied through the pachymetry [6].

Furthermore, ethnic differences in the central corneal thickness have been described throughout the European, Hong Kong Chinese, Chinese, Japanese and Americans [5]. Also, data on central corneal pachymetry maps in the Korean adult population have been reported in myopia [8]. But age and sex related changes in the central and peripheral corneal thickness and curvature of Korean young population have not been reported yet. In this study, we research characteristics of the distribution of the central and peripheral corneal thickness and curvature in a Korean young population by using pachymetry data obtained from the Orbscan II system.

The purpose of this study is therefore to identify the age and sex related changes in the central and peripheral corneal thickness and curvature in Korean young subjects

\footnotetext{
*Corresponding author: pasuhwa@eulji.ac.kr

Color versions of one or more of the figures in this paper are available online.
} 
Age and Sex Related Changes in Corneal Thickness and Anterior Corneal Curvature -.. - Dong-Hee Lee et al.

TABLE 1. The distribution of corneal thicknesses within $3 \mathrm{~mm}$ corneal region in Korean young population subjects

\begin{tabular}{|c|c|c|c|c|c|c|c|c|c|c|}
\hline \multirow[t]{2}{*}{ Ages } & \multirow{2}{*}{ Sex } & \multicolumn{9}{|c|}{ Region(Mean \pm SD) } \\
\hline & & $\mathrm{C}$ & $\mathrm{N}$ & $\mathrm{S} / \mathrm{N}$ & $\mathrm{S}$ & $\mathrm{S} / \mathrm{T}$ & $\mathrm{T}$ & $\mathrm{I} / \mathrm{T}$ & I & $\mathrm{I} / \mathrm{N}$ \\
\hline \multirow{2}{*}{$4-9$} & $\mathrm{M}$ & $\begin{array}{l}562.382 \\
\pm 36.852\end{array}$ & $\begin{array}{l}576.912 \\
\pm 38.387\end{array}$ & $\begin{array}{l}583.956 \\
\pm 38.863\end{array}$ & $\begin{array}{c}590.25 \\
\pm 38.551\end{array}$ & $\begin{array}{l}587.015 \\
\pm 42.189\end{array}$ & $\begin{array}{l}575.882 \\
\pm 38.371\end{array}$ & $\begin{array}{c}576.75 \\
\pm 38.958\end{array}$ & $\begin{array}{l}587.618 \\
\pm 39.764\end{array}$ & $\begin{array}{l}577.441 \\
\pm 38.772\end{array}$ \\
\hline & $\mathrm{F}$ & $\begin{array}{r}548.883 \\
\pm 28.794 \\
\end{array}$ & $\begin{array}{r}563.163 \\
\pm 30.398 \\
\end{array}$ & $\begin{array}{r}571.242 \\
\pm 31.609 \\
\end{array}$ & $\begin{array}{l}578.374 \\
\pm 31.945 \\
\end{array}$ & $\begin{array}{r}572.651 \\
\pm 30.639 \\
\end{array}$ & $\begin{array}{l}564.147 \\
\pm 31.038 \\
\end{array}$ & $\begin{array}{l}562.869 \\
\pm 31.003 \\
\end{array}$ & $\begin{array}{l}563.455 \\
\pm 31.343 \\
\end{array}$ & $\begin{array}{l}562.754 \\
\pm 31.844 \\
\end{array}$ \\
\hline \multirow{2}{*}{$10-19$} & $\mathrm{M}$ & $\begin{array}{l}550.621 \\
\pm 31.620\end{array}$ & $\begin{array}{l}569.759 \\
\pm 31.643\end{array}$ & $\begin{array}{l}576.853 \\
\pm 31.092\end{array}$ & $\begin{array}{l}581.526 \\
\pm 29.370\end{array}$ & $\begin{array}{l}578.026 \\
\pm 30.913\end{array}$ & $\begin{array}{l}573.121 \\
\pm 33.421\end{array}$ & $\begin{array}{l}569.940 \\
\pm 34.165\end{array}$ & $\begin{array}{l}565.681 \\
\pm 32.399\end{array}$ & $\begin{array}{l}565.578 \\
\pm 31.709\end{array}$ \\
\hline & $\mathrm{F}$ & $\begin{array}{l}556.276 \\
\pm 50.344\end{array}$ & $\begin{array}{l}578.276 \\
\pm 50.344\end{array}$ & $\begin{array}{l}583.985 \\
\pm 39.604\end{array}$ & $\begin{array}{l}588.560 \\
\pm 38.958\end{array}$ & $\begin{array}{r}585.147 \\
\pm 44.695\end{array}$ & $\begin{array}{l}580.509 \\
\pm 52.591\end{array}$ & $\begin{array}{l}577.285 \\
\pm 56.697\end{array}$ & $\begin{array}{l}574.744 \\
\pm 52.912 \\
\end{array}$ & $\begin{array}{l}575.562 \\
\pm 43.828\end{array}$ \\
\hline \multirow{2}{*}{$20-16$} & $\mathrm{M}$ & $\begin{array}{l}540.259 \\
\pm 48.986\end{array}$ & $\begin{array}{l}566.148 \\
\pm 45.220\end{array}$ & $\begin{array}{l}573.444 \\
\pm 45.256\end{array}$ & $\begin{array}{l}579.694 \\
\pm 48.076\end{array}$ & $\begin{array}{l}574.796 \\
\pm 49.754\end{array}$ & $\begin{array}{r}565.482 \\
\pm 53.512\end{array}$ & $\begin{array}{l}561.760 \\
\pm 53.074\end{array}$ & $\begin{array}{l}559.009 \\
\pm 50.679\end{array}$ & $\begin{array}{l}560.593 \\
\pm 46.984\end{array}$ \\
\hline & $\mathrm{F}$ & $\begin{array}{r}531.290 \\
\pm 45.823\end{array}$ & $\begin{array}{l}556.342 \\
\pm 38.466\end{array}$ & $\begin{array}{l}562.329 \\
\pm 43.353\end{array}$ & $\begin{array}{l}567.434 \\
\pm 49.719\end{array}$ & $\begin{array}{l}590.026 \\
\pm 99.114\end{array}$ & $\begin{array}{l}555.934 \\
\pm 43.352\end{array}$ & $\begin{array}{l}550.592 \\
\pm 38.784\end{array}$ & $\begin{array}{l}548.605 \\
\pm 35.828\end{array}$ & $\begin{array}{l}551.895 \\
\pm 35.088\end{array}$ \\
\hline
\end{tabular}

* $\mathrm{P}=0.000(\mathrm{C}$ vs N, C vs S/N, C vs S, C vs S/T, C vs T, C vs I/T, C vs I, C vs I/N)

$\mathrm{C}=$ central, $\mathrm{N}=$ nasal, $\mathrm{S} / \mathrm{N}=$ superior nasal, $\mathrm{S}=$ superior, $\mathrm{S} / \mathrm{T}=$ superior temporal

$\mathrm{T}=$ temporal, $\mathrm{I} / \mathrm{T}=$ inferior temporal, $\mathrm{I}=$ inferior, $\mathrm{I} / \mathrm{N}=$ inferior nasal

by the Orbscan II topography system.

\section{MATERIALS AND METHODS}

Subjects: This study included a total of 292 Korean young people. They had no ocular disease, medication, keratoconus, contact lens wear, or refractive surgery. The subjects' ages ranged from 5 to 26 years. To exclude ocular disease, we tested the visual acuity and the IOP, and examined using a slit-lamp and funduscopy. Also to exclude strong changes in corneal physiology, our measurements were made from 10:00 A.M. to 12:00 A.M.

Examination: The central corneal thickness and the peripheral corneal thicknesses at a radial distance of $3 \mathrm{~mm}$ from the central cornea were obtained by measurements of the Orbscan II topography system (Bausch \& Lomb, USA). The measurements were obtained for each eye. The Orbscan II was used for corneal topography measurements while the subjects were seated silently in a test room. The subjects were asked to keep both eyes open and to focus on a light source in the center of the scan field. The measurements automatically occurred when the correct alignment and focus of eye were achieved. The corneal thicknesses at the center of cornea, the thinnest point, and the points $3.0 \mathrm{~mm}$ temporal, superior temporal, superior, superior nasal, nasal, medial nasal, inferior nasal, nasal from the pupil were recorded automatically and analyzed by a SPSS 14 and a Microsoft Excel program. All measurements were made between 10:00 A.M. and 12:00 A.M. During the test, the temperature ranged from $18^{\circ}$ to $21^{\circ} \mathrm{C}$, and the humidity ranged from $40 \%$ to $50 \%$. Only the scans with the quality factor of $95 \%$ were selected for the analysis.

Data analysis: Analyses were performed by using SPSS software. The Pearson correlation and t-test were used to

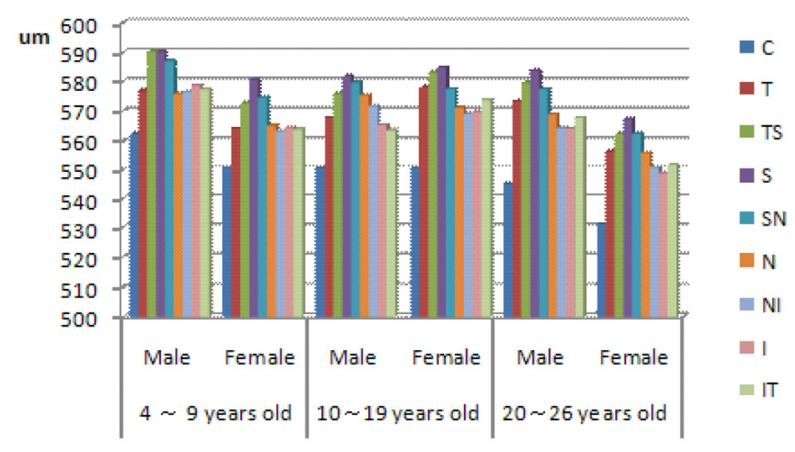

FIG. 1. Comparative of the central and peripheral corneal thicknesses in $3 \mathrm{~mm}$ corneal region of a Korean young population. $(\mathrm{C}=$ central, $\mathrm{N}=$ nasal, $\mathrm{S} / \mathrm{N}=$ superior nasal, $\mathrm{S}=$ superior, $\mathrm{S} / \mathrm{T}=$ superior temporal $\mathrm{T}=$ temporal, $\mathrm{I} / \mathrm{T}=$ inferior temporal, $\mathrm{I}=$ inferior, $\mathrm{I} / \mathrm{N}=$ inferior nasal.)

compare measurements in the different age and sex related data.

\section{RESULTS}

We acquired the corneal topographic data from 584 eyes of 292 subjects (146 boys, 146 girls) with the mean age of $14.648 \pm 5.590$ years (range $4-26$ years). The mean age for the subjects was $15.54 \pm 6.007$ years (range 4-26 years) for males and $13.755 \pm 5.970$ years (range $4-26$ years) for females. There was no significant difference in the mean age between males and females ( $p>0.5$, t-test). The age and sex distributions of the corneal central thickness and paracentral corneal thickness for these subjects were summarized in Table 1, and Figure 1. 
The average corneal central thickness was $549.527 \pm 40.626$ $\mu \mathrm{m}$ (range, 549-406 $\mu \mathrm{m}$ ) and 547.240 $\pm 43.733 \mu \mathrm{m}$ (range, $428-450 \mu \mathrm{m})$ for males and females, respectively. There was no significant difference in the mean corneal central thickness between males and females $(\mathrm{P}=0.126$, $\mathrm{T}$-test $)$. Also the mean paracentral corneal thickness did not differ significantly between males and females $(\mathrm{p}=0.991$. T-test). However, the corneal central thickness was thinner than any 8 paracentral corneal thicknesses with statistical significance $(\mathrm{p}=0.000$, t-test $)$ in all subjects.

In all subjects, Table 2 showed that the correlation between ages in the central and eight paracentral regions had no significant differences ( $p>0.5$ test). However, Table 3 showed that the correlation between ages in the corneal thickness of males had a statistical significance between 4-9 years old and 10-19 years old in the central, inferior, and inferior nasal corneal thickness( $\mathrm{p}<0.05$, T-test). On the other hand, females had a statistical significance between 4-9 years old and 20-26 years old in the central, inferior temporal, and inferior corneal thickness $(\mathrm{p}<0.05$, T-test $)$.

Figure 2 shows that males 4-9 years old had thicker central and paracentral corneal thicknesses than those of other ages. However, Figure 3 shows that males 10-19 years old had thicker central and paracentral corneal thicknesses than other ages had.

The average anterior corneal curvatures in the males and females were $8.020 \pm 0.499 \mathrm{~mm}$ (range, 7.49-9.12 mm) and $7.989 \pm 0.245 \mathrm{~mm}$ (range, 7.20-8.48 mm). The average anterior

TABLE 2. Correlation between ages in the central and eight paracentral regions

\begin{tabular}{cccccccccc}
\hline \hline Ages & $\mathrm{C}$ & $\mathrm{N}$ & $\mathrm{S} / \mathrm{N}$ & $\mathrm{S}$ & $\mathrm{S} / \mathrm{T}$ & $\mathrm{T}$ & $\mathrm{T} / \mathrm{I}$ & $\mathrm{I}$ & $\mathrm{I} / \mathrm{N}$ \\
\hline $4-9$ & $0.145^{*}$ & $0.120^{*}$ & $0.171^{*}$ & $0.247^{*}$ & $0.153^{*}$ & $0.176^{*}$ & $0.117^{*}$ & $0.132 *$ & $0.132^{*}$ \\
$10-19$ & 0.989 & $0.282 *$ & $0.412^{*}$ & $0.176^{*}$ & 0.825 & 0.712 & 0.826 & 0.693 & $0.306^{*}$ \\
$20-26$ & $0.247^{*}$ & $0.104^{*}$ & $0.119^{*}$ & $0.180^{*}$ & $0.191^{*}$ & $0.248^{*}$ & $0.223^{*}$ & $0.142^{*}$ & $0.114^{*}$ \\
\hline
\end{tabular}

$* \mathrm{p}<0.5$

$\mathrm{C}=$ central, $\mathrm{N}=$ nasal, $\mathrm{S} / \mathrm{N}=$ superior nasal, $\mathrm{S}=$ superior, $\mathrm{S} / \mathrm{T}=$ superior temporal

$\mathrm{T}=$ temporal, $\mathrm{I} / \mathrm{T}=$ inferior temporal, $\mathrm{I}=$ inferior, $\mathrm{I} / \mathrm{N}=$ inferior nasal

TABLE 3. Correlation between ages and sex in the central and eight paracentral regions

\begin{tabular}{|c|c|c|c|c|c|c|c|c|c|c|}
\hline Sex & Ages & $\mathrm{C}$ & $\mathrm{N}$ & $\mathrm{S} / \mathrm{N}$ & $\mathrm{S}$ & $\mathrm{S} / \mathrm{T}$ & $\mathrm{T}$ & $\mathrm{T} / \mathrm{I}$ & I & $\mathrm{I} / \mathrm{N}$ \\
\hline \multirow{3}{*}{$\mathrm{M}$} & $4-9$ vs $10-19$ & $0.035^{*}$ & 0.284 & 0.275 & 0.143 & 0.112 & 0.337 & 0.122 & $0.022 *$ & $0.042 *$ \\
\hline & $10-19$ vs $20-26$ & 0.199 & 0.951 & 0.872 & 0.780 & 0.510 & 0.298 & 0.235 & 0.484 & 0.841 \\
\hline & $4-9$ vs $20-26$ & 0.043 & 0.726 & 0.658 & 0.457 & 0.256 & 0.330 & 0.157 & 0.134 & 0.322 \\
\hline \multirow{3}{*}{$\mathrm{F}$} & $4-9$ vs $10-19$ & 0.949 & 0.144 & 0.268 & 0.684 & 0.731 & 0.852 & 0.834 & 0.701 & 0.326 \\
\hline & $10-19$ vs $20-26$ & 0.305 & 0.070 & 0.078 & 0.221 & 0.474 & 0.566 & 0.415 & 0.227 & 0.110 \\
\hline & $4-9$ vs $20-26$ & $0.014^{*}$ & 0.191 & 0.149 & 0.129 & 0.107 & 0.144 & $0.048^{*}$ & $0.017 *$ & 0.053 \\
\hline
\end{tabular}

$* \mathrm{P}<0.05, \mathrm{M}=$ male, $\mathrm{F}=$ female

$\mathrm{C}=$ central, $\mathrm{N}=$ nasal, $\mathrm{S} / \mathrm{N}=$ superior nasal, $\mathrm{S}=$ superior, $\mathrm{S} / \mathrm{T}=$ superior temporal

$\mathrm{T}=$ temporal, $\mathrm{I} / \mathrm{T}=$ inferior temporal, $\mathrm{I}=$ inferior, $\mathrm{I} / \mathrm{N}=$ inferior nasal

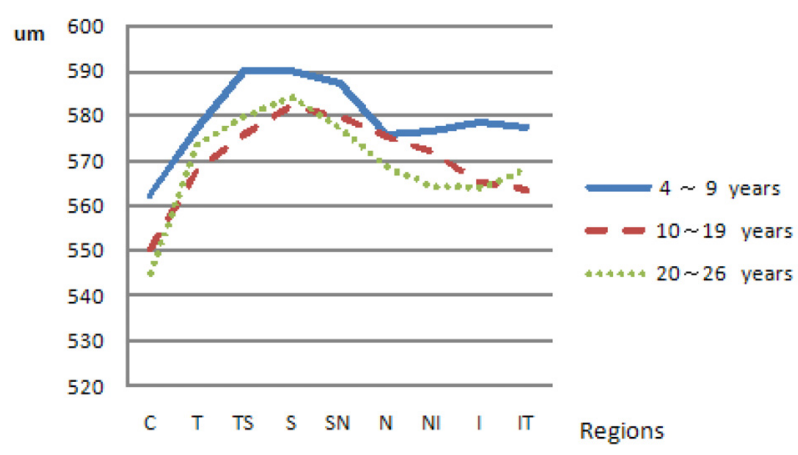

FIG. 2. Distribution of the central corneal thickness and peripheral corneal thicknesses of eight regions in $3 \mathrm{~mm}$ central corneal region in males.

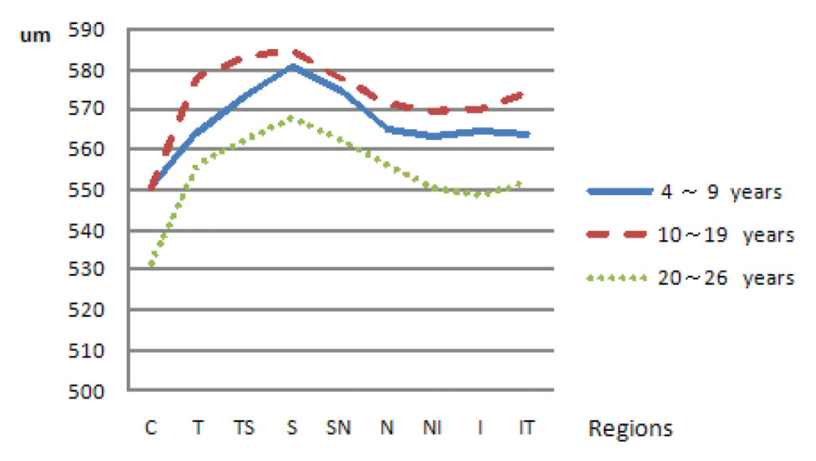

FIG. 3. Distribution of the central corneal thickness and peripheral corneal thicknesses of eight regions in $3 \mathrm{~mm}$ central corneal region in females. 
TABLE 4. The mean anterior corneal curvature(ACC) and central corneal thickness(CCT) in 3 mm corneal region of all subjects.

\begin{tabular}{cccccc}
\hline \hline Ages & Sex & $\mathrm{n}$ & $\begin{array}{c}\text { Mean } \pm \text { SD } \\
\text { ACC }(\mathrm{mm})\end{array}$ & $\begin{array}{c}\text { Mean } \pm \text { SD } \\
\text { CCT }\end{array}$ & P values \\
\hline $4-9$ & M & 34 & $8.06 \pm 0.35$ & $562.38 \pm 36.85$ & 0.777 \\
& F & 50 & $8.08 \pm 0.24$ & $548.88 \pm 28.79$ & 0.593 \\
$10-19$ & M & 58 & $7.99 \pm 0.69$ & $550.62 \pm 31.62$ & 0.518 \\
& F & 59 & $7.91 \pm 0.22$ & $551.92 \pm 53.80$ & 0.383 \\
& M & 54 & $8.03 \pm 0.30$ & $540.26 \pm 48.99$ & 0.110 \\
& F & 38 & $7.99 \pm 0.25$ & $531.29 \pm 45.82$ & $0.038^{*}$ \\
\hline
\end{tabular}

$* \mathrm{P}<0.05, \mathrm{M}=$ male, $\mathrm{F}=$ female

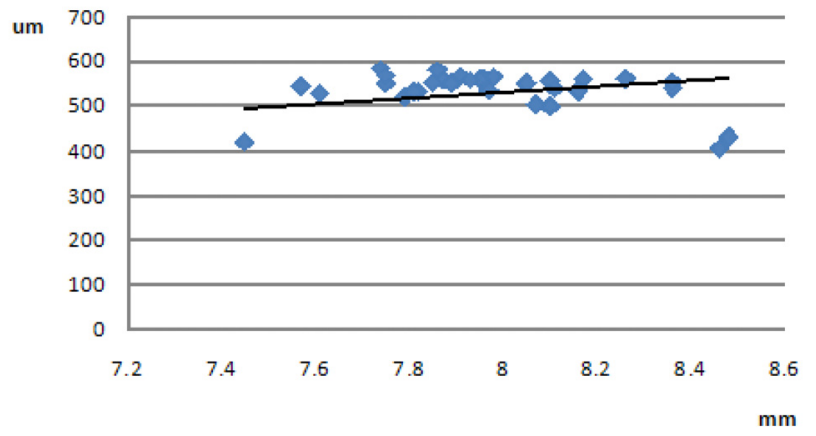

FIG. 4. Relationship between the anterior corneal curvature and central corneal thickness in twenty year old females.

curvature did not differ significantly among the different age groups and sex. The average anterior curvature and central corneal thickness had only significant differences from 20-26 years old age $(p>0.05)$. The anterior corneal curvature and central corneal thickness in $3 \mathrm{~mm}$ corneal region were not related significantly among age and sex (Table 4). However, the correlation between CCT and ACC in twenty year old females had a significantly difference $(\mathrm{p}<0.05)$. Also, CCT $(x)$ and $\mathrm{ACC}(\mathrm{Y})$ were positively correlated, and correlation coefficient was moderate $\left(y=66.367+0.014 x, R^{2}=0.047 ; p=0.037\right.$; Fig. 4).

\section{DISCUSSION}

In this study, we carried out and analyzed the data from the central and paracentral corneal measurements in order to know the relationship of age and sex in the corneal thickness and anterior corneal curvature of a Korean young population. For this study, we used the Orbscan System because it easily measures the corneal thickness across the entire corneal topographic morphology [3]. We believe that Orbscan measurements of corneal thickness are more reliable than ultrasound pachymetry tests. The defect of ultrasound pachymetry is that the target of fixation light and the test area are dependent on the user [9], therefore, some results of ultrasound pachymetry are unstable. On the other hand, we made special care to avoid outside condition changes that could change the physiologic corneal status because under stable physiologic states the corneal thickness is constant
[10]. We took special care to avoid situations where corneal hydration might be altered because such conditions have been associated with more changes in corneal thickness [6]. Therefore, the temperature range during the test was maintained at the same conditions (ranging from $18^{\circ} \mathrm{C}$ to $21^{\circ} \mathrm{C}$ ) also the same applied for relative humidity (ranging from $40 \%$ to $50 \%$ ). Furthermore, we performed the corneal topography test at a constant time to avoid the diurnal variation in corneal morphology [11]. In the last few years, knowledge of corneal thickness has become increasingly important in clinical diagnosis and treatment [12]. The clinical parameter is important for correct interpretation of Goldmann tonometry data [12]. So, pachymetry using the Orbscan II System has become increasingly established. It shows good reproducibility and accuracy [13].

In this study, we present specific reference values for the Orbscan II system and investigate the influence of age and sex on the corneal anatomy. In our study, the mean central corneal thickness for all subjects was $547.532 \pm 44.529$ $\mu \mathrm{m}$. Some studies showed that the mean central corneal thickness was 551 um for Caucasians [14], 550 um for Hispanics [14], 544 um for Japanese [15], 532 um for African Americans [14] from 0 to 18 years of age. We found out that the mean central corneal thickness of Koreans was similar to Japanese. We think that perhaps these results were affected by the similar factor of genetics of the same Mongolian race. Autzen's [16, 17] study showed that the central corneal thickness increased slowly and reached the adult level at 3 or 5 years of age. Sawa [18] reported that he found no difference between the 3-month old infants and the 20 to 29 year old adults. Muir et al. [19] suggested that central corneal thickness slowly increased in children up to the age of 5 and then decreased between ages 10-14 years. Hussein et al. [14] reported that central corneal thickness increased in children until age 9 years and then decreased between 10 and 14. In our study, central corneal thickness slowly decreased from 4 to 26 year olds. In normal subjects, Florian et al. [12] did not find that the sex had any significant influence on the central corneal thickness, also we could not find any significant difference between males and females in our studies. However, Florian et al. [12] found a significant difference in the corneal thickness of the 10 to 39 year old patients and 40 to 80 year old 
patients. Florian et al. [12] thought that the normal values show that an increase in human central corneal thickness measured by the Orbscan was a function of age. But the age-dependent difference in the corneal thickness remains unclear because different studies $[4,5,21]$ carried out on a large sample of subjects presented contradictory results. Price et al. [22] had no detected differences in the central corneal thickness between female and male subjects. However Foster et al. [21] reported that the central corneal thickness values decreased with each decade of life. Nevertheless, Cosar et al. [5] detected significant differences in the central corneal thickness among hyperopic, myopic, emmetropic subjects, emmetropic corneas being the thinnest. Lam and Douthwaite [4] reported that the central cornea of emmetropic subjects had smaller mean thickness values than the paracentral regions. In our study, we found that the central corneal thickness becomes thinner as the age increases from 4 to 9 years old and 10 to 19 years old in males, and from 4 to 9 years old and 20 to 26 years old in females. We think that these changes of corneal thickness were affected by corneal hydration [6]. La Rossa et al. [23] reported that young Europeans differ in corneal thickness values between populations. They observed that African American patients had lower central corneal thickness values than Caucasian patients. Moreover, Doughty and Zaman [24] carried out a meta-analysis to generate a normal value for the central corneal thickness in the adult human eye and they found that the mean value of central corneal thickness in human pachmetry studies was close to $535 \mu \mathrm{m}$. However, the cross-study groups of average central corneal thickness may be considered marginally lower in the Japanese and the Greenland Eskimos. According to our studies, the central corneal thickness was similar to Japanese population of emmetropic subjects. The central and peripheral corneal thickness knowledge of corneal data is becoming more important. Also the increasing use of corneal diagnosis of refractive surgery is responsible for this. Information about corneal thickness thus permits the postoperative refractive power to be predicted within certain limits.

In our studies, we cannot identify a statistically significant difference for paracentral corneal thickness between males and females. However, we can find out that the central and paracentral corneal thickness had statistically significant differences in all subjects $(\mathrm{P}=0.00)$. In this study, we found that the peripheral corneal thicknesses at a radial distance of $3 \mathrm{~mm}$ from the central cornea are asymmetric. Also we found the largest mean peripheral cornea thickness at the superior $(580.717 \pm 40.736 \mu \mathrm{m})$ and superior temporal (576.183 $\pm 43.412 \mu \mathrm{m})$ while the lowest mean peripheral cornea thickness were inferior $(564.442 \pm 44.190 \mu \mathrm{m})$ and inferior nasal $(565.099 \pm 40.751 \mu \mathrm{m})$. These results correlate well with the work of Florian et al. [12]. Also they found that the peripheral corneal thickness had a decrease with increasing age. On the other hand, we found that the inferior corneal thickness had statistically significant changes between males 4-9 years old and 10-19 years old, between females 4-9 years old and 20-26 years old. In contrast, no statistically significant change was found superior, nasal, and temporally. Our results found no significant differences in corneal thickness between females and males at the central and paracentral corneal thickness. Florian et al. [12] reported that the peripheral corneal thickness may also prove useful in evaluating a better match between donor and host cornea, and the information related to anatomic changes also seems important to us with regard to refractive surgery. We think that central and peripheral corneal thickness was very useful information in regards to corneal diagnosis and treatment in clinic. Juan et al. [9] reported that the analysis of the differences in thickness measured at 7 corneal sites showed that the central cornea of all subjects had smaller mean thickness values than paracentral sites, as was observed previously in several studies carried out in ametropic subjects [3-8]. More peripheral thickness values have been reported to be an average of $21 \%$ greater than central corneal values [24], moreover, the superior nasal cornea was thicker than the other corneal regions, our results being consistent with previous studies [3, 6, 7, 9]. The Erickson et al. [25] suggested that the increased values of the superior cornea were attributed by the fact of chronically hypoxic, in which this hypoxia was caused by partial coverage of the superior cornea by the upper eyelid. However, several studies have not researched differences in central corneal thickness between female and male subjects $[2,6,22]$. Nevertheless, unlike other studies [3-8], we analyzed the difference between the mean central and paracentral thickness obtained of each eye or individual. The difference between the central thickness and the paracentral thickness was also analyzed. However, the differences at superior nasal and inferior nasal cornea were significant. One explanation for differences in the corneal thickness between males and females subjects could be the effect of sexual hormones, i.e. it seems that female corneal thickness values could be affected by sexual hormones, and it was hypothesized that the tropic effect of estrogens can alter corneal thickness [8]. However, we did not find out possible effect of sexual hormones by including only females who were not taking any kind of medication. In the corneal thickness and curvature studies, Fernandez et al. [26] indicated that the change in central and paracentral corneal thickness was strongly correlated with corneal curvature, except for $2 \mathrm{~mm}$ nasal and superior semi-meridians. Our study showed that the relationship between the central corneal thickness and anterior curvature was statistically significant from 20 to 26 years of age $(\mathrm{p}<0.05)$.

In conclusion, we believe that the groups of values of Orbscan pachymetry data were suitable for comparative study of corneal thickness in the Korean young population because they represent an age cross-section of the normal population. Also, the topographic study of healthy Korean young subjects has shown that the difference between ages and sex of the central corneal thickness have similar results. However, the relationship between the central corneal thickness and paracentral corneal thickness has significant differences $(p=0.000$, t-test) for all ages and sexes of subjects. On the other 
hand, the age and sex related changes in central corneal thickness and anterior corneal curvature in all subjects had no statistically significant difference, except from 20-26 years of age $(p>0.05)$.

\section{CONCLUSION}

We find that the corneal thickness change in a Korean young population has no relationship between age and sex. However, the relationship between the mean central corneal and the eight paracentral corneal thicknesses has strong statistical differences in all subjects. Also age and sex related changes in the central corneal thickness and the anterior corneal curvature in all subjects have no statistically significant difference, except from $20-26$ years old ( $>>0.05$ ). This information provides a suitable reference basis for future studies in the young population of Asia and the development of examination tools for corneal refractive surgery.

\section{REREFENCES}

1. K. R. Wilhelmus, J. Sugar, R. A. Hyndiuk, and R. D. Stulting, "Corneal thickness changes during herpes simplex virus disciform keratitis," Cornea 23, 154-157 (2004).

2. A. M. Bron, C. Creuzot-Garcher, S. Goudeau-Boutillon, and P. d'Athis, "Falsely elevated IOP due to increased CCT," Graefes Arch. Clin. Exp. Ophthalmol. 227, 220-224 (1999).

3. M. M. Marsich and M. A. Bullimore, "The repeatibility of corneal thickness measures," Cornea 19, $792-795$ (2000).

4. A. K. Lam and W. A. Douthwaite, "The corneal-thickness profile in Hong Kong Chinese," Cornea 17, 384-388 (1998).

5. C. B. Cosar and A. B. Sener, "Orbscan corneal topography system in evaluating the anterior structures of the human eye," Cornea 22, 118-121 (2003).

6. Z. Liu and S. C. Pflugfelder, "Corneal thickness is reduced in dry eye," Cornea 18, 403-407 (1999).

7. Z. Liu, A. J. Huang, and S. C. Pflugfelder, "Evaluation of corneal thickness and topography in normal eyes using the Orbscan corneal system," Br. J. Ophthalmol. 83, 774-778 (1999).

8. C. Sorrention, P. Affinito, F. M. Raso, M. Loffredo, P. Merlino, A. Loffredo, S. Palomba, and C. Nappi, "Effect of hormone replacement therapy on postmenopausal ocular function," Minerva Ginecol. 50, 19-24 (1998).

9. S.-G. Juan A, L.-P. Antonio, A. Luis, M. S. Rahhal, and M.-S. Franciso, "Anatomic study of the corneal thickness of young emmetropic subjects," Cornea 23, 669-673 (2004).

10. M. Bohnke, P. Chavanne, R. Gianotti, and R. P. Salathe, "Continuous non-contact corneal pachymetry with a high speed reflectometer," J. Refract. Surg. 14, 140-146 (1998).

11. Y. Feng, J. Varikooty, and T. L. Simpson, "Diurnal variation of corneal and corneal epithelial measured using optical coherence tomography," Cornea 20, 480-483 (2001).

12. R. Florian, S. Anke, B. Christine, and E. Carl, "Age-related changes in central and peripheral corneal thickness-determination of normal values with the Orbscan II topography system," Cornea 26, 1-5 (2007).

13. P. Cho and S. W. Cheung, "Repeatability of corneal thickness measurements made by a scanning slit topography system," Ophthalmic Physiol. Opt. 22, 505-510 (2002).

14. M. A. Hussein, E. A. Paysse, N. P. Bell, D. K. Coats, K. M. B. McCreery, D. D. Koch, S. Orengo-Nania, D. Baskin, and K. R. Wilhelmus, "Corneal thickness in children," Am. J. Ophthalmol. 138, 744-748 (2004).

15. H. Akiko, S. Miho, T. Kinnichi, M. K. Yuka, A. Ryo, and H. Yoshihiro, "Central corneal thickness in Japanese children," Jpn. J. Ophthalmol. 53, 7-11 (2009).

16. T. Autzen and L. Bjornstrom, "Central corneal thickness in full-term newborns," Acta Ophthalmol. (copenh) 67, 719-720 (1989).

17. T. Autzen and L. Bjornstrom, "Central corneal thickness in full-term newborns," Acta Ophthalmol. (copenh) 69, 251-252 (1991).

18. M. Sawa, "Measurement of corneal thickness," Jap. Rev. Clin. Ophthalmol. (Ganka Rinsho Iho) 80, 177-184 (1986).

19. K. W. Muir, J. Jin, and S. F. Freedman, "Central corneal thickness and its relationship to intraocular pressure in children," Ophthalmology 111, 2220-2223 (2004).

20. L. Jr. Modis, A. Langenbucher, and B. Seitz, "Evaluation of normal cornea using the scanning-slit topography/pachymetry system," Cornea 23, 689-694 (2004).

21. P. J. Foster, J. Baasanhu, P. H. Alsbirk, D. Munkhbayer, D. Uranchimeg, and G. J. Johnson, "Central corneal thickness and intraocular pressure in Mongolian population," Ophthalmology 105, 969-973 (1998).

22. F. W. Price, D. L. Koller, and M. O. Price, "Central corneal pachymetry in patients undergoing laser in situ keratomileusis," Ophthalmology 106, 2216-2220 (1999).

23. F. A. La Rosa, R. L. Gross, and S. Orengo-Nania, "Central corneal thickness of Caucasian and African Americans in glaucomatous and nonglaucomatous populations," Arch Ophthalmol. 119, 23-27 (2001).

24. M. J. Doughty and M. L. Zaman, "Human corneal thickness and its impact on intraocular pressure measures: a review and meta-analysis approach," Surv. Ophthalmol. 44, 367-408 (2000).

25. P. Erickson, T. L. Comstock, and S. G. Zantos, "Is the superior cornea continuously swollen?," Clin. Exp. Optom. 85, 168-171 (2002).

26. M. J. G. Fernandez, A. D. Rey, A. Cervino, and E. YebraPimentel, "A comparison of corneal of two pachymetric systems: slit-scanning and ultrasonic," CLAO J. 28, 221-223 (2002). 